\title{
Capacity Building Initiatives in Mineral Education in Southern Africa: Opportunities for Collaboration
}

\author{
Godfrey Dzinomwa ${ }^{1 *}$, Harmony K. Musiyarira ${ }^{1}$, Kawunga Nyirenda ${ }^{2}$, Raymond Suglo ${ }^{3}$ \\ ${ }^{1}$ Department of Mining and Process Engineering, Namibia University of Science and Technology, Windhoek, Namibia \\ ${ }^{2}$ Copperbelt University, Zambia \\ ${ }^{3}$ Botswana International University of Science and Technology, Botswana
}

\begin{abstract}
Many countries in Southern Africa are generally endowed with a wealth of minerals. For example, South Africa and Zimbabwe are host to approximately $80 \%$ of the world's Platinum Group Minerals (PGMs) and chromite resources. Vast deposits of coal, both thermal and metallurgical, occur and are mined in significant quantities in Botswana, Malawi, Mozambique, South Africa, Zimbabwe and Zambia. However, the region has over the years experienced a shortfall in skilled personnel as well as well-resourced training institutions to convert the comparative advantage arising from the rich mineral endowment to a competitive advantage through efficient extraction, beneficiation and value addition. In recent years, Governments in the sub-region have responded to this unfavorable situation by opening a number of universities and other tertiary institutions focussing on educating and training a new generation of mineral professionals. This study reviewed the recent developments in the region and assessed the extent to which capacity shortfalls are being addressed in the minerals sector. The methodology included questionnaires and interviews, and the analysis was mainly qualitative. The main findings of the study were that although several mineral education institutions were being opened in the region, there is an inadequate number of professionals in the mining and minerals field in the region for teaching and research, and there are few wellequipped modern facilities for teaching and research such as laboratories and lecture rooms. This situation presents an opportunity for collaborative initiatives, not only within the region but internationally, aimed at addressing these shortfalls and ensuring that appropriate skills are developed for the mining industry and also for the academic institutions.
\end{abstract}

Keywords: capacity building, challenges, collaboration, sustainability, research

\section{Introduction}

Many countries in Southern Africa are generally endowed with a wealth of mineral resources. For example, South Africa and Zimbabwe are host to approximately $80 \%$ of the world's Platinum Group Minerals (PGMs) and chromite resources. Vast deposits of coal, both thermal and metallurgical, occur and are mined in significant quantities in Botswana, Malawi, Mozambique, South Africa, Zimbabwe and Zambia. Over the years, Angola, Botswana, the Democratic Republic of Congo, Lesotho, Namibia, South Africa and Zimbabwe have provided a significant share of the world's rough diamonds, and according to the Kimberly Process Certification Scheme (KPCS), these countries produced a combined $48.8 \%$ of the world's rough diamonds by volume, contributing $55.6 \%$ of the value in 2016. Base metals, especially nickel and copper, are extracted profitably in Botswana, the Democratic Republic of Congo, South Africa, Zambia and Zimbabwe. Other mineral resources which occur in large proportions in Southern African countries include aluminium, uranium, gold, iron ore, lithium, tantalite, tin, manganese, limestone and zinc.
In recent years, the region has emphasized the need for beneficiation and value addition of its minerals. However, the region has over the years experienced a shortfall in skilled personnel as well as well-resourced training institutions to convert the comparative advantage arising from the rich mineral endowment to a competitive advantage through efficient extraction, beneficiation and value addition. In the last decade, Governments in the subregion have responded to this unfavourable situation by opening a number of universities and other tertiary institutions focusing on educating and training a new generation of mineral professionals. This study reviewed the recent developments in the region and assessed the extent to which capacity shortfalls are being addressed in the minerals sector.

Industrial growth and competitiveness hinges on technological advancement and skills development is the panacea to the lack of technological advancement of any nation or region. Training and skills development is the cornerstone of the mining industry's 'efficiency, effectiveness, development, growth and sustenance' (Musiyarira et al 2013).

* Corresponding Author: Godfrey Dzinomwa, Email: gdzinomwa@ nust.na, phone: +26461 2072076

Copyright @ 2018 Canamaple Academia Services, http://press.camdemia.ca

DOI: 10.15273/ijge.2018.03.029 
Depressed mineral commodity prices have a significant impact on the minerals industry, particularly from a sustainability perspective (Tesh et al 2015). In this regard, tertiary institutions offering mineral education across the world face enormous sustainability challenges (Phillips 1999, Galvin et al 2001). This is a global problem that is not limited to the developing world. Most of the mineral rich countries within Southern Africa have also made it a condition that they should be in the lead in the training and skills development of their nationals as shown in Figure 1.

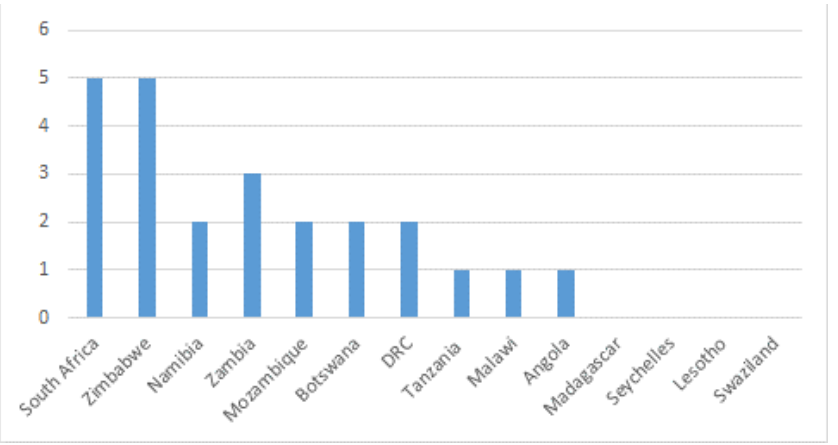

Figure 1 The Number of Mining Schools in Southern Africa (Salvador 2015)

Mining education programmes globally have traditionally seen recruitment and survival at risk during industry down cycles. For example, at the turn of 2000 many North American as well as Australian mineral education programmes were close to extinction (Scoble 2003). It is unrealistic to believe that the mineral education sector can be relevant and sustainable whilst remaining quarantined from these dramatic developments. In order to ensure a smooth supply of skills to the industry, it is necessary that collaboration be promoted between universities in different countries, the industry and governments.

\section{Overview of Mineral Education in Southern Africa}

Many African states have established universities and schools of mines for training in geology, mining engineering and extractive metallurgy. However, there are inadequate numbers of academics with postgraduate qualifications to teach at these new universities and to carry out research (Gudyanga 2015). This paper takes a closer look at the various training institutions in the region and the challenges being experienced, and suggests solutions, focusing on the need for greater relevance to the regional mining industry. Sections 2.1 to 2.7 present an overview of the mineral education in the region.

\subsection{Namibia}

In response to the mining boom, the University of Namibia (UNAM) and Namibia University of Science and Technology (NUST), formerly known as the Polytechnic of Namibia (PON), introduced Minerals Engineering degree programmes in 2008/2009 and they are in the process of developing professional and further education programmes in order to meet future mining industry skills needs and building a workforce that incorporates sustainable development into operations. The Namibia University of Science and Technology offers Bachelor of Engineering in Mining and Bachelor of Engineering in Metallurgy degrees, while the University of Namibia offers degree programmes in Geology, Mining Engineering and Metallurgical Engineering. The two mining departments were established in 2009 and their graduates have since successfully entered the professional market. The Department of Mining and Process Engineering at the Namibia University of Science and Technology has pursued an aggressive expansion programme by establishing links with various expert teaching and research professionals from renowned institutions around the world. These linkages have fostered meaningful collaboration between the University and its partners in the form of staff and student exchanges, as well as research.

\subsection{Zimbabwe}

Zimbabwe, in particular, has faced serious skills flight as a result of the economic slowdown spanning for almost two decades, with most of the personnel going to South Africa, New Zealand, Australia, the United Kingdom and other countries. The skills flight has been so serious that the number of graduates produced from the Zimbabwean institutions was not adequate to fill in the void that has been left. The institutions offering training and the various disciplines that are being offered by the training institutions to the Zimbabwean minerals industry are as follows:

(1) Zimbabwe School of Mines (Geology, Mining and Metallurgy up to Higher Diploma level);

(2) University of Zimbabwe (Geology, Mining and Metallurgy);

(3) Manicaland University of Applied Sciences (Mining and Metallurgy);

(4) Midlands State University (Mining and Metallurgy);

(5) Gwanda State University (Mining and Metallurgy).

As the case in the rest of the region, the institutions suffer from inadequate staff, infrastructure and other resources. The new Government has been calling on private businesses to establish various joint ventures aimed at providing infrastructure in universities. The University of Zimbabwe set up a Confucius Institute aimed at teaching the Chinese language as a means to strengthening collaboration in education, trade and other areas with China.

\subsection{South Africa}

The start of higher education in South Africa took place in Kimberly in 1896 with the establishment of a vocationally based School of Mines in Kimberly. This was effectively a Polytechnic whose purpose was to provide high level manpower to the developing diamond mining industry in Kimberly (Musingwini 2015). Today, more training institutions have evolved and this has led to the formation of the University of Witwatersrand, University of Pretoria, University of Venda and the University of Johannesburg. Later, the distance Education University of Southern Africa 
(UNISA) was established in Pretoria. All these institutions have passionately maintained their mining related courses. A number of Technikons and colleges are being upgraded to universities of technology. While this may generally prove to be a good development, in some instances, however, it creates a gap in practical skills as the number of technicians produced has dwindled. Currently there are five universities offering minerals related programmes namely:

(1) University of Witwatersrand;

(2) University of Johannesburg;

(3) University of Pretoria;

(4) University of Venda;

(5) University of South Africa.

\subsection{Mozambique}

The Mozambican Minerals industry has been growing fast in recent years. The coal industry in the Tete province has experienced some rapid growth, reaching record production of 18 million tonnes in 2017 and there is a critical need for skills development to cater for the sector. At University level the province has the Polytechnic Institute of Tete while at college level there is one School - the "Instituto Médio de Geologia e Minas/ Technical College. The "Instituto Industrial e Comercial de Pemba", the "Centro de Formação Profissional INEFP de Pemba" and the "Escola Técnica Profissional de Macomia" are developing curricula for the oil and gas sector at college level. The main Universities such as Eduardo Mondlane University teach mainly (geology, exploration geology, and applied geology) while the Wunitiva University delivers a Geology and Mining Engineering degree, and they are both in Maputo. Recently the University of Lurio (UNILurio), in the North of Mozambique, and the Pedagogic University (Beira and Nampula) are offering classical geology programs. The Eduardo Mondlane University has started Master and $\mathrm{PhD}$ programs in Mineral Resources Management, Master in Petroleum Engineering and has established a regional (Southern and Eastern Africa) Centre of Excellency in Oil and Gas which is funded by the World Bank. The Instituto Médio de Geologia e Minas, developed curricula for the mining, geology, mineral processing, and topography at college level.

\subsection{Zambia}

Zambia has three mining schools namely Copperbelt University, University of Zambia and Copperstone University. The Copperbelt University has three minerals related programmes namely, Mining Engineering, Metallurgy, Geology and Survey. The Mining Department offers a number of programmes which include Diploma in Mining Engineering, Diploma in Mine Ventilation, Small Scale Mining, and a Bachelor of Engineering in Mining Engineering. The Department, through the School of Graduate Studies, also offers postgraduate programmes both by taught courses and research work (CBU 2018a). The Metallurgy Department offers the Bachelor of Engineering in Metallurgical Engineering and the Mineral Engineering, These programmes were introduced in 2001 and 2014 respectively to run concurrently with three year diploma metallurgy programmes (CBU 2018b). The Geology and Survey Department has been offering only one diploma programme in Surveying and it introduced two degree programmes in 2016. The programmes include a degree in Mining and Exploration Geology and a degree in Geomatics Engineering. The diploma programme in surveying continues to be offered by the department and there are plans to revise and rename it a Diploma in Geomatics (CBU 2018c).

The University of Zambia is the biggest state university in Zambia. The mining industry still remains the mainstay of Zambia's economy and will continue to play an important role in the development of the country (UNZA 2018). It is in the context of an acute shortage of graduate manpower for this vital industry that the School of Mines was established in 1973 as one of the Schools of the University of Zambia. The three departments of the School, namely, Geology, Mining Engineering, and Metallurgy and Mineral Processing reflect the most important disciplines involved in the search for ores, their recovery from the ground and the extraction of metals from these ores. The School of Mines offers postgraduate programmes leading to the degree of Master of Mineral Sciences. The School also offers Doctor of Philosophy $(\mathrm{PhD})$ degrees in all the three mining disciplines (Besa 2015). The overall objective of the training programmes is to produce graduates with competencies in the science and technology of processing minerals and metals, process design of chemical and metallurgical operations, management of production systems, economic evaluation of engineering processes, and environmental and energy management.

\subsection{Botswana}

The Botswana International University of Science and Technology (BIUST) was established in the mid-2000s and offers 5 year training programmes and the graduates hold Bachelor of degrees in Mining Engineering, Geological Engineering, as well as Materials and Metallurgy Engineering. The University had its first graduates in these two programmes in February 2018. It also has postgraduate programmes in both Mining Engineering and Geological Engineering, which are 2-year MEng programmes and 3year $\mathrm{PhD}$ programmes. The vision of the Department is to produce world-class professionals in the fields of mining and geological engineering.

The University of Botswana (UB) does not offer Metallurgy but offers Mineral Engineering (formerly called Mineral Processing). The University of Botswana has been offering Mining Engineering until 2017 under a 3+2 arrangement with Missouri University of Science and Technology (MUST) in the USA, where students covered the first 3 years at UB and the last 2 years at MUST. The first group of mining Engineering students to do the entire programme (5 years) at UB are expected to complete it in 2019. UB has been offering Diplomas in Mining Engineering and Mineral Engineering since 2000. However, these programmes were suspended in 2015 and Geology is being offered by the Geology department in the Faculty of Science. 


\section{Challenges}

The survey conducted in this study established some of the challenges being experienced by most of the universities as follows:

(1) Lack of infrastructural facilities such as lecture rooms, and laboratories as well as student accommodation and transport;

(2) Difficulties in recruiting sufficient academic staff due to a wide gap between conditions of service in industry and in the universities;

(3) Lack of funding for professorial chairs to spearhead research and innovation.

In a study of the sustainability of mineral education in Namibia, (Musiyarira et al 2013) identified seven interactive factors that could affect the sustainability of mineral education. These were: (1) the funding covering the essential needs of the institutions, (2) the number of graduates matching the needs of the mining and related industries, (3) the quality and quantity of students enrolling for the programmes, (4) alliances and partnerships of the educational institutions, (5) the quality and quantity of academic staff, (6) sound infrastructures, and (7) a welldeveloped and dynamic curriculum. It is important to note that these factors were not only unique to the Southern African mineral education system but they were worldwide trends as noted by other researchers (Wagner 1999, Galvin et al 2001, Moudgil 2006, Cawood 2011). The only difference was that all institutions were affected differently and within their context of development.

Over the past two decades, there has been a rapid growth in the number of students in tertiary institutions in Africa. This has posed a challenge to the sustainable financing of higher education since the growth in numbers was not matched by funding levels. On an average, Africa has allocated about $0.78 \%$ of its GDP and around $20 \%$ of its current public expenditure on education over the last 15 years (World Bank Report 2010, Devarajana et al 2011). Decline in public expenditure per student is having an adverse impact on the quality of education programmes.

\section{Way Forward}

The main findings of the study were that although several mineral education institutions were being opened in the region, there is an inadequate number of professionals in the mining and minerals field for teaching and research, and there are few well-equipped modern facilities for teaching and research such as laboratories and lecture rooms. In some cases, student accommodation and transport is also inadequate. This is caused mainly by dwindling Government financial support, a trend which has also been observed in other universities within Africa and the western world and it has become a big constraint in attaining sustainability of education in general. The dwindling state funding has the biggest impact on new departments of universities which are trying to make their first steps to build sustainable academic programmes regarding both teaching and research.

Figure 2 and Sections 4.1 to 4.7 highlight the strategy that needs to be carried out in order to ensure the sustainability of the mineral engineering programmes in the region.

\subsection{Smart partnerships}

Literature studies reveal that engineers and scientists that are required to lead the minerals industry into a competitive position will emerge from innovative educational environments and from institutions that are forming smart partnerships and that understand the need to collaborate and share resources. The current fragile state of tertiary

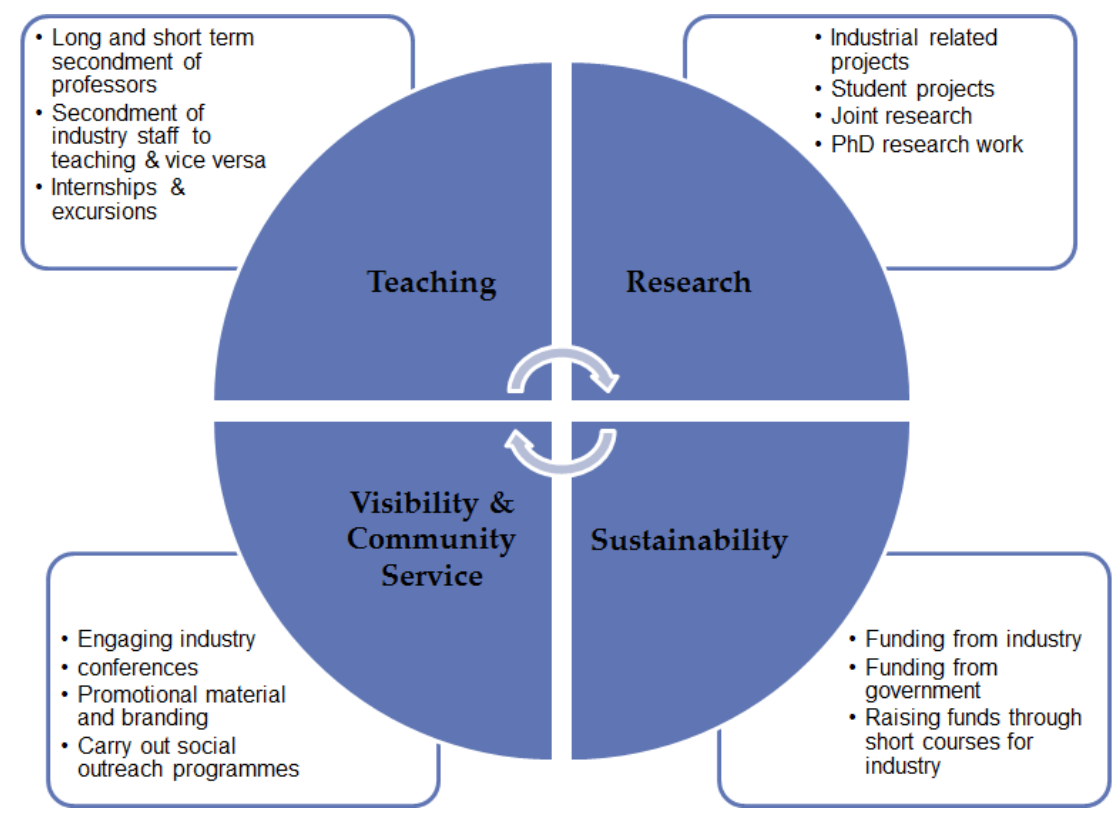

Figure 2. A collaborative strategy to ensure the sustainability of mineral education 
education in the region must provide incentives for networking and collaboration rather than competition since the institutions are offering similar programmes. This situation presents an opportunity for collaborative initiatives, not only within the region but internationally, aimed at addressing the shortfalls and ensuring that appropriate skills are developed for the mining industry and also for the academic institutions. There are opportunities for joint supervision of postgraduate students. This has the added benefit where the more established universities in Zambia and South Africa can have their senior academics collaborating with the upcoming academics in other universities in postgraduate supervision and research.

\subsection{Harmonisation of curricula}

Universities in the region should find a common ground in the harmonisation and mutual recognition of their curricula but still maintaining a distinctive flavour or context of their environment. This harmonisation of curricula poses a strategy which will enhance the sharing of human resources either physically or through e-learning platforms that will address the staff shortages within other universities. In this regard, the universities should be encouraged to develop curricula that is relevant not only for the national industry, but also for the region to give graduates a wider range of opportunities. This will promote national and regional mobility of students and staff as well. The curricula offered should be more inclusive rather than highly specialized and restrictive ones, and it should have room for promoting entrepreneurship skills among graduates to enable them to create employment and not necessarily to look for jobs. For effective harmonization of curricula to occur, it is important that efforts be made to reduce language barriers through staff and student exchanges and the adoption of common languages across borders. The Society of Mining Professors (SOMP) provides a good platform for standard and high quality exchange of staff.

\subsection{Regional forum for academics}

In light of the pressing challenges facing the mineral education programmes, it will be beneficial to set up a platform for the heads of mining and related disciplines to meet and set up a vehicle for collaboration. This forum can be facilitated through the Southern African Institute of Mining and Metallurgy (SAIMM) in collaboration with the Society of Mining Professors (SOMP). This should enable the forum to have a database of teaching and research areas of the university staff and this will provide an opportunity and a platform for sharing of key human resources in terms of teaching and research. SAIMM and SOMP could play a leading role to facilitate the formation of Heads of Mining and Metallurgy Schools forum.

\subsection{Retention strategies}

Staff turnover is high in most of the training institutions and lessons should be learnt from the Zambian universities with regards to staff retention. Strategies for staff retention may include providing staff incentives which are competitive internationally which include:

(1) Sourcing of research grants;

(2) Improving remuneration packages so that the gap between industry and academic institutions is reduced;

(3) Defined succession and development plan for the millennials.

\subsection{Elimination of duplication of programmes}

The training in the region needs to be coordinated so that there is minimal duplication amongst institutions where adequate capacity does exist and each institution should have an area of excellence. This would allow staff and students along the lines of China's Double first class initiative which emphasizes the creation of world class universities and disciplines. Without adequate and continuous surveys to establish industry requirements, there is a danger of the Mining and Metallurgical Engineering programmes being oversubscribed in the industry and flooding the market. One of the challenges of the training institutions is to correctly focus on the number of graduates in order to strike a balance between the number of graduates produced and the market demand. Currently there is an imbalance in some countries between the graduates produced and the regional Minerals Industry's capacity to absorb them.

\subsection{Industry and government engagement}

In order to remain relevant to the development needs of their nations and to the international community in general, universities should always remain in close contact with their Industries and Governments. Networking and establishing industrial and business partners, both nationally and internationally should be encouraged by:

(1) Sourcing funding of (a) professorial chairs to spearhead applied research and innovation aimed at promoting development, and (b) scholarships for talented students who will contribute to industrial development;

(2) Involvement of industry partners in the determination of curricula of programmes so that contemporary areas of focus are addressed. This could be achieved through the appointment of industry partners to Departmental or Faculty advisory boards;

(3) Negotiating with government authorities to give investment partners tax reliefs, lower import duties and tariffs for mining and processing equipment;

(4) Providing opportunities for students to secure vacation and other industrial attachments so that they gain experience.

\subsection{Exploring the One Belt One Road (OBOR) Initiative}

The One Belt and One Road (OBOR) initiative was proposed by China to promote the connectivity of Asian, European and African continents and their adjacent seas to establish and strengthen partnerships among the countries along the Belt and Road, set up all-dimensional, multi-tiered and composite connectivity networks, and realize diversified, independent, balanced and sustainable 
development in these countries (NDRC 2015). Although Southern Africa lies outside the OBOR route, it is important that existing platforms such as the Forum on China-Africa Cooperation (FOCAC) be utilized to facilitate the inclusion of the region in the initiative. The One Belt One Road (OBOR) initiative and the Double First Class initiative present a unique opportunity for collaboration between mineral education universities in Southern Africa and mineral education universities and industries along the economic route. The goal of building world class universities and disciplines is a shared outcome for both regions, and will be realized through the promotion of extensive cultural and academic exchanges, and cooperation. According to NDRC (2015), China provides 10,000 government scholarships to the countries along the Belt and Road every year and it aims to increase cooperation in science and technology, establish joint labs (or research centers), international technology transfer centers and maritime cooperation centers, promote sci-tech personnel exchanges, cooperate in tackling key sci-tech problems, and work together to improve sci-tech innovation capability.

\section{Conclusions}

Most of the countries in Southern Africa are generally endowed with a wealth of minerals. These include platinum group minerals, diamonds, gold, lithium, iron ore, uranium and base metals especially copper, nickel and cobalt bearing minerals. However, the region has over the years experienced a shortfall in skilled personnel as well as wellresourced training institutions to convert the comparative advantage arising from the rich mineral endowment to a competitive advantage through efficient extraction, beneficiation and value addition. In recent years, Governments in the sub-region have responded to this unfavorable situation by opening a number of universities and other tertiary institutions focussing on educating and training a new generation of mineral professionals. This study reviewed the recent developments in the region and assessed the extent to which capacity shortfalls were being addressed in the minerals sector. The main findings of the study are that although several mineral education institutions are being opened in the region, there are inadequate numbers of professionals in the mining and minerals field in the region for teaching and research, and there are few well-equipped modern facilities for teaching and research such as laboratories and lecture rooms. This situation presents an opportunity for collaborative initiatives, not only within the region but also internationally, aimed at addressing the identified shortfalls and ensuring that appropriate skills are developed for the mining industry and for the academic institutions that develop the skills.

\section{Acknowledgement}

We would like to thank the heads of mining schools in Southern Africa for readily availing information for this study.

\section{References}

Besa, B., 2015. Strategies for addressing challenges of Mining Schools: A case study of University of Zambia, School of Mines. 3rd regional conference, Society of Mining Professors, Windhoek, Namibia, 28 September to 2 October.

Cawood, F.T., 2011. Threats to the South African minerals sector-an independent view on the investment environment for mining. Journal of the Southern African Institute of Mining and Metallurgy, 111(7): 469 - 474.

Copperbelt University (CBU), 2018a. https://www.cbu.ac.zm/smms/. Accessed 28 March 2018.

Copperbelt University (CBU), 2018b. https://www.cbu.ac.zm/smms/mining-engineeringdepartment/. Accessed 28 March 2018.

Copperbelt University (CBU), 2018c. https://www.cbu.ac.zm/smms/geology-surveydepartment/. Accessed 28 March 2018.

Devarajana, S., C. Mongab, and T. Zongoc, 2011. Making higher education finance work for Africa. Journal of African Economies, 20 (AERC Supplement 3): 133154.

Galvin, J.M. and P.J. McCarthy, 2001. Mining education: driven by global impacts. Proceedings Explo 2001. Hunter Valley, NSW, pp9-14.

Gudyanga, F., 2015. Pan-African Minerals University of Science and Technology (PAMUST). 3rd Regional Conference, Society of Mining Professors, Windhoek, Namibia, 28 September to 2 October.

Moudgil, B., 2006. Communication with SME team. Mining Engineering, pp. 1 - 5.

Musingwini, C., 2015. An overview of the Wits School of Mining Engineering, 3rd Regional Conference, Society of Mining Professors, Windhoek, Namibia, 28 September to 2 October.

Musiyarira, H., D. Tesh, and G. Dzinomwa, 2013. Challenges of promoting sustainability in the Namibian minerals education. Proceedings of the 6th International Conference on Sustainable Development in the Minerals Industry, Milos Island, Greece, 30 June - 3 July, pp. $25-30$.

National Development and Reform Commission of China (NDRC), 2015. Vision and Actions on Jointly Building Silk Road Economic Belt and 21st-Century Maritime Silk Road.

Phillips, H.R., 1999. Mining education in South Africa past, present and future. CIM Bulletin, 92(1033): 101 106.

Salvador, M, 2015. Strategies for addressing challenges facing mining schools, Eduardo Mondlane University of Mozambique, 3rd regional conference, Society of Mining Professors, Windhoek, , Namibia, 28 September to 2 October.

Scoble, M., 2003. The crisis in mining education. Annual Conference, Prospectors and Developers Association of Canada, Toronto.

Tesh, D., H. Musiyarira, G. Dzinomwa, and H. Mischo, 2015. Interventions for ensuring sustainability of the 
minerals education programmes at the Polytechnic of Namibia. Southern African Institute of Mining and Metallurgy Journal, 114 (12): 1055-1058.

University of Zambia (UNZA), 2018.

http://mines.unza.zm/?p=380. Accessed 02 March 2018
Wagner, H., 1999. How to address the crisis of mining engineering education in the western world? Mineral Resources Engineering, 8(4): 471 - 481.

World Bank Report, 2010. Financing Higher Education in Africa. Washington, D.C.: World Bank. 